\title{
Understanding Moral Injury and Belief Change in the Experiences of Police Online Child Sex Crime Investigators: an Interpretative Phenomenological Analysis
}

\author{
Kit Tapson $^{1}$ (D) $\cdot$ Mark Doyle $^{2}$ (D) $\cdot$ Vasileios Karagiannopoulos ${ }^{3}$ (D) Peter Lee $^{4}$ (D)
}

Accepted: 10 June 2021 / Published online: 30 June 2021

(c) Crown 2021

\begin{abstract}
Little is known about the psychological and physiological impacts of moral injury within organizational contexts such as Internet Child Abuse Teams (hereafter abbreviated to ICAT), who are repeatedly exposed to trauma through viewing and grading graphic images of children being sexually abused. The aims of the current research were to explore the key features of, and contributing factors to, moral injury and trauma as experienced by Internet Child Abuse Teams, how these manifested and how these factors can be mitigated. Six participants were recruited from ICATs located at two police constabularies. Data were gathered using semi-structured interviews and analysed using interpretative phenomenological analysis. Findings indicated that the moral injury experienced by the participants was predominantly attributable to repeated exposure to traumatising images, with too little decompression time. Dysfunctional coping mechanisms, most commonly substance misuse, cognitive avoidance of distressing thoughts and emotional numbing, amplified the psychological and physical symptoms of anxiety. For many ICAT investigators, such tactics were attempts to manage the moral violations arising from their work and experienced as moral injury. These findings will be used to inform psychological review systems and interventions within policing.
\end{abstract}

Keywords Moral injury $\cdot$ Police $\cdot$ Internet Child Abuse Teams $\cdot$ Interpretative phenomenological analysis $\cdot$ Psychological review

Moral injury refers to a significant traumatic event in which an individual witnesses, perpetrates or fails to act against actions that contravene personal moral codes that can result in significant psychological distress (Litz et al. 2009). Police Internet Child Abuse Teams (ICAT) are exposed to high volumes of traumatic and distressing content (College of Policing 2020, p. 3). To date, a qualitative study exploring

Kit Tapson

kit.tapson@port.ac.uk

1 Creative and Cultural Industries, University of Portsmouth, Room 3.19, Eldon Building, Middle Street, Portsmouth PO1 2DJ, Hampshire, UK

2 Occupational Health, Belfast Health and Social Care Trust, Belfast, Northern Ireland

3 Institute of Criminal Justice Studies, University of Portsmouth, Portsmouth, UK

4 Creative and Cultural Industries, University of Portsmouth, Portsmouth, UK the lived experiences of police online investigators and their potential for moral injury, trauma and belief change from screen mediated harm has yet to be conducted.

\section{What Is Moral Injury?}

The term moral injury originated from research exploring the experiences of military veterans, undertaken by Shay and colleagues (Shay 2010; Shay and Munroe 1998). Based on participant narratives, these researchers categorised moral injury by defining three characteristic components: (i) a betrayal of what is morally right, (ii) by someone who holds legitimate authority and (iii) in a high-stakes situation (Shay 2014, p. 183). Contributing to Shay's definition, other researchers (Litz et al. 2009; Nash 2019) found that individual failure to prevent moral violation or witnessing of traumatic life events, 'transgress[ed] deeply held moral beliefs and expectations' (Litz et al. 2009, p. 697), placing ascendency with individual action. Such subjective 
disruption was capable of fragmenting the ethical aspirations rooted in the foundation of being, for example, cultural, organizational and group-based rules about fairness, spiritual or religious beliefs and the value of life (Litz et al. 2009; Litz and Kerig 2019; Nash 2019). The perception of having contravened the foundations of moral conscience and values this way (Barnes et al. 2019) produced intense emotional guilt and shame (Litz et al. 2009), and for some, a sense of betrayal, anger and profound moral disorientation (Molendijk 2018).

According to Garrigan et al. (2018), how to act in a situation within a moral domain requires awareness that there are moral rules attached, weighing these against stored moral schemas and interpreting relevant features, before decisionmaking. However, enactment of a preferential behaviour may depend on other contextual and situational factors. For example, police officers are motivated by a moral commitment to protect society and to maintain peace and order (Caldero and Crank 2011). Yet, their original moral incentives may be eroded by organizational culture (Crank et al. 2007), leading to a decline in personal integrity and shifts in their personal values (Harr 2005) consistent with the cognitive dissonance characterising moral injury (LaMotte and Murphy 2017).

\section{Moral Injury in Policing}

Throughout their careers, police officers are exposed to an estimated 900 traumatic events (McQuerrey-Tuttle et al. 2019), which, coupled with organizational stressors, contribute to mental ill health (McCreary et al. 2017) and post-traumatic depreciation (Zięba et al. 2019). Such consequences are reflected in the cognitive triad of trauma (Center for Substance Abuse Treatment 2014) where changes to views of self; relationships with others; and future or philosophy of life are affected.

Repeated exposure to work-related traumatic incidents impedes the ability for many police officers to cope (Bartol and Bartol 2004), with the concurrent risk of developing psychopathology and moral injury (McCormak and Riley 2016). Symptoms include guilt, frustration, depression, self-harm, shame, loss of spirituality/religiosity or a sense of rejection (Currier et al. 2015). Experiencing a trauma itself does not inevitably result in moral injury. Of importance is how individuals integrate their assessment of a traumatic event into their schema, since poor integration leads to lingering psychological distress, because of avoidance behaviours that inhibit successful assimilation (Keane et al. 1985). Although effective in the short term, avoidance impedes corrective learning experiences related to amorality, sustaining negative appraisal and the psychosocial impact of moral conflict. Interpretation is also intrinsic to the development of a moral injury, as this appraisal process determines whether the event generates dissonance with the individual's moral framework, their worldview and their actions (Griffin et al. 2019). Such dissonance is at the forefront of ICAT investigations where police officers are primarily assigned to watch graphic images ranging from still photographs of young children, to explicit video (with sound) of infants being tortured and raped (Burns et al. 2008), that challenges the foundations of their moral framework.

Radical increases in internet use have enabled heinous crime such as online child abuse. In the United Kingdom (UK), during the first month of lockdown (April, 2020), 8.8 million attempts were made at accessing child abuse content online (Grierson 2020, Watchdog reveals 8.8 million attempts to access online child abuse in April, para. 9). Such escalating caseloads have led to the growth of specialised internet child abuse units across policing departments (Burruss et al. 2018), inevitably shaping individuals' working experiences (Holt et al. 2012; Rivard et al. 2002). Consequently, here is a need to understand the unique factors that influence their workplace experiences.

Continual exposure to such distressing content creates an environment in which burnout, compassion fatigue and secondary trauma become more likely (College of Policing 2020, p. 9). Notably, a study by Powell et al. (2014) found that viewing difficult material was not appraised by participants as particularly distressing (they considered this an integral work task), but rather, that it impeded their job performance. How it hampered their performance though was not explained. Additionally, ICAT investigators engage in investigative role-playing where they must put themselves 'in the minds' of a perpetrator or victim. Unsurprisingly, exposure to constant human suffering erodes normal coping mechanisms, placing officers at higher risk of developing secondary traumatic stress (Bourke and Craun 2014), and disengagement from their emotions in order to remain objective (Evans et al. 1993; Pogrebin and Poole 1991). Such detachment is amplified by archetypal masculinity, embedded in the ethos of policing, which inhibits emotional expression and amplifies presumptions that officers are invincible (Papazoglou 2013; Rudofossi 2007).

Evidentially, ICAT investigators undertake a role that exposes them to the risk of developing moral injury, trauma and belief change, this empirical literature generating questions that merit further analysis. Overall, this research sought greater understanding as to how the study population make sense of their experiences. It therefore explored how these contributed to the development of moral injury and trauma, how their experiences influenced changes to beliefs and behaviour, the most influential circumstances for the development of moral injury and trauma and the coping mechanisms utilised to alleviate these. Given the intention to make sense of 
experience, interpretative phenomenological analysis was selected as the methodology to guide data gathering and analysis as this is ideally suited to the study of subjective experience. Interviews were undertaken with 6 ICAT investigators from 2 constabularies in the UK, using open-ended questions to facilitate the participant's narrative and to enable the double hermeneutic that also recognises the researcher's contribution to interpretation. Data were analysed in-depth using the framework outlined by Smith and Osborn (2008), where multiple readings of the transcripts gave rise to the subordinate and superordinate themes considered most representative of the participants' concerns.

\section{Study Purpose, Objectives and Aims}

The current study aimed to explore screen-mediated moral injury and trauma as experienced by ICAT investigators. The question guiding the research was: what are the key features of, and contributing factors to, moral injury and trauma as experienced by child exploitation investigators, how are these manifested in relation to changes in behaviour and how might these factors be mitigated?

Given the subjective nature of experience, our qualitative methodology of choice was interpretative phenomenological analysis (IPA). Phenomenology is an approach to research that seeks to describe the essence of a phenomenon by exploring it from the perspective of those who have experienced it (Neubauer et al. 2019). It is especially valuable to explore complex topics that are emotionally laden and abstruse (Smith and Osborn 2015), such as moral injury. Using IPA the researcher is equally implicated, as it is their conceptions that are required to make sense of the participant's personal world through interpretation, a process known as a double hermeneutic. Hermeneutic phenomenology refers to the idea that individuals' realities are invariably influenced by the world in which they live (Lopez and Willis 2004). Framing IPA this way locates it within the framework of critical realism, a branch of philosophy that distinguishes between the real and observable world (Smith and Osborn 2008). The rational for this philosophical line of enquiry was therefore that it allowed us to explore the nuanced dimensions of moral injury from both the experiences of the police officers taking part and from the perspective of policing culture, in a way that complemented the research aims.

\section{Method}

\section{Participants}

To demonstrate a diverse sample, participants included three ICAT officers from a constabulary in the South of England and three from a constabulary in Northern England, five males and one female. Diversity derived from the polarised geographical locations, the cultural differences inherent in these divergent locations and their varied organizational structures.

\section{Recruitment Process}

An email was circulated to 14 Digital Forensic Group and 16 ICAT members which included an embedded Joint Information Systems Committee (JISC) link to the participant information sheet, a consent form, an interview schedule and a debriefing form with a list of supporting organizations. Participants completed a brief demographic questionnaire, including their contact details and length of service, the latter since only police officers with a service history longer than 6 months were considered for inclusion.

Based on homogenous purposive sampling, a non-probability approach was used in order to reach a targeted sample of ICAT investigators in keeping with the study objectives. Because of duty commitments regarding Coronavirus, five of the original eight respondents withdrew, leaving a sample size of three. Recruitment was therefore broadened to include three additional participants from another constabulary. IPA stipulates no prescribed or ideal sample size, however, studies are generally conducted on small samples ranging from one to five participants; hence the concept of saturation does not apply (Smith and Osborn 2008).

\section{Ethical Considerations}

Given the sensitivity of the research, each interview began by introducing the participants to therapeutic grounding techniques to be used following each interview as an emotional management technique. The two researchers undertaking data collection and analysis come from different professional and occupational backgrounds. One, a humanistic counsellor with significant experience in qualitative approaches related to mental health, the other, a cognitive behavioural therapist and psychologist with experience rooted in psychosocial risk factors for mental health issues. Both have considerable previous knowledge of using IPA and experience of research within policing contexts. Their personal opinion of this population has not always been informed by positive experiences-one researcher having experienced political conflict between the police, armed forces and civilians in a conflict zone and the other having witnessed a confrontational episode between a family member and the police. This varied expertise enhanced data analysis by bringing different philosophical viewpoints of the phenomenon to interpretation. 


\section{Data Gathering}

Data were gathered using one-to one, semi-structured interviews of between 70 and 122 min of duration, during April and May 2020. Because of the Coronavirus, the interviews were conducted using Google Meets, a virtual platform that enables audio recordings to be saved directly to a secure database. With prior contact with the participants limited to email exchanges, building trust into the researcher/participant relationship had to be undertaken online. At the mercy of functioning $\mathrm{Wi}-\mathrm{Fi}$ and without ethical permission for video capture, the researchers were left with verbal engagement only. This seemed to enable, rather than inhibit, the relationship, possibly because telling their stories brought several participants to tears, an emotional expression they felt more comfortable releasing when they could not be seen.

The interview procedure, as outlined by Smith and Osborn (2008), involved the construction of an interview schedule, using open-ended questions to avoid leading participants. These began with simple questions to put the participants at ease i.e. What brought you to this particular role? What are the positive and negatives of the role you undertake? then progressing to more searching topics about trauma and moral injury i.e. What experiences of trauma have you had in your life prior to this role? What within your role have you encountered that has had a lasting impression? The questions were formulated based on a literature review of peer-reviewed research about policing, online child abuse investigation, trauma, moral injury and belief change, published between 2009 and 2019. These dates were selected to (i) capture the most contemporary changes to the psychological review systems within policing, (ii) include up-to-date information about the technological changes that have effected online child abuse investigation and (iii) include the impact of recent upsurges in online paedophilia. Literature was selected based upon an in-depth search of multiple databases including; Scopus, Web of Science, Pub Med, Criminology Collection, National Social Sciences Database and PsychINFO. The questions also derived from previous research exploring moral injury (Lee 2018). The interview guide was used to support exploration of the research topic but not to direct it. This necessitated adapting the questions allowing a flexible response to the interviewee's replies. In this way, the interviewer and participant interacted together in an ever developing conversation.

\section{Data Analysis}

The researchers conducted a debriefing session following each interview to discuss concerns, initial perceptions of the interview process and potential biases that may have effected data gathering, for example, whether, or how, their therapeutic training may have influenced assessment. Fidelity was upheld as both held to professional psychotherapy standards of authentically representing individual narratives, for example, using the participants' own words to represent the codes.

Initially, NVivo 12 was used to order the data. However, due to the Coronavirus, the two researchers were prevented from meeting face to face and ethical adherence to heightened security considerations prohibited email exchanges of classified data. They therefore defaulted to manual analysis. Whilst this approach derailed completion targets, manual analysis enabled familiarization with the data that NVivo may not have.

To ensure credibility when using IPA, a robust study should afford trustworthiness by offering a transparent evidence trial that maintains an authentic connection between data and interpretation (Smith et al. 2009). This required engaging with the hermeneutic circle to both give voice to the participant's narratives and the researchers' interpretations.

The first of the six transcripts was read repeatedly and closely, familiarising the researchers with the narrative. Preliminary annotations were noted. At this stage, comments were guided by similarities and differences in the narrative but also, reiterations, emphases and contradictions. This approach facilitated what Smith (1999) argues as central to an idiographic perspective. It enabled us to see patterns of convergence and divergence whilst providing a level of analysis that facilitated recognition of individual participant experiences. Next, the researchers revisited the transcript to document emerging theme headings, where the initial notes were transformed into concise phrases. Similar themes emerged as the transcript was parsed and so allocated the same theme heading. A table was constructed to populate the emergent themes along with the text supporting them. Connections between themes were noted, discussed and reordered accordingly. Superordinate themes were identified based on clusters of subthemes and represented in a table. During the review process, themes which neither fitted the emerging structure or that were not rich in evidence within the transcript were dropped. This procedure was repeated with the subsequent transcripts. Both researchers conferred throughout.

\section{Coding}

To encapsulate the essence of the participants' lived experiences, the transcripts were then coded. This process involved identifying themes in the participants' accounts and attaching labels (codes) to index them (for example, see Table 1 
showing the coding samples in relation to identity). Through regular discussion, the researchers documented and standardised coding decisions by assigning top-level codes to one transcript, ordered in a coding table.

The researchers met repeatedly to consider their coding selections, until consensus was reached. These sub-codes were then assigned to the remaining five transcripts. This iterative process resulted in each transcript being reviewed four times, a process which also illuminated areas of convergence and divergence in the participants' narratives such as the different coping mechanisms used to manage their distress.

\section{Findings}

The data analysis resulted in four superordinate themes that were categorised as (1) impact of organizational role and environment, (2) influences of investigative role on identity, (3) coping mechanisms to manage distress and (4) influences of trauma on personality, self and wellbeing. Each of the superordinate themes were subdivided into subordinate themes (see Table 2), each explored below with illustrative participant quotes. To ensure transparency and authenticity, the verbatim quotes selected to illuminate the findings were decided collaboratively, demonstrating fidelity to the ideographic focus of IPA. Following each quote, the participant's pseudonym appears preceded by 'interview with'. The participant pseudonyms were as follows: MI7541, MI022, MI183, MI866, MI036 and MI391.

\section{Impact of Organizational Role and Environment}

Under this superordinate theme, two subthemes emerged reflecting the participants' overarching concerns: psychological review and professional support and workplace environment (Table 2).

\section{Subtheme 1: Psychological Review and Professional Support}

Due to their level of trauma exposure, the participants recognised psychological review as key to their wellbeing. They all agreed however that the generic police psychological screening available to them was inadequate. '... [A]bout eighty per cent of us go in, and tick those boxes, and walk back out, because we just don't find it [...] fit for purpose at all' (interview with MI7541). Moreover, there were fears about confidentiality with many believing it would have consequences for career progression, making the service a potential risk-factor rather than a support mechanism. 
Table 2 The participant pseudonyms were as follows: MI7541, MI022, MI183, MI866, MI036 and MI391

\begin{tabular}{ll}
\hline Superordinate theme & Subtheme \\
\hline Impact of Organizational Role and environment & Psychological Review and Professional Support \\
Influences of Role on Identity & Workplace Environment \\
& Identity \\
Coping Mechanisms to Manage Distress & Searching for meaning and Detachment \\
& Peer and Familial Support \\
Influences of Trauma on Personality, Self and Wellbeing & Adaptive and Maladaptive Coping \\
& Breaking Point and Burn out \\
& Two Worlds: Balancing Darkness and Light \\
& Personality traits and post-traumatic depreciation \\
& Trauma and Effects \\
\hline
\end{tabular}

\section{Subtheme 2: Workplace Environment}

The participants identified that alongside exposure to traumatic media, the difficulty placed on them related to workplace environment including: staffing, time related targets and workload. The workplace environment included both supportive and unsupportive management. About the latter, one participant related how, ' $[\mathrm{O}]$ ne of my colleagues was in [....] his session for forty five minutes and my line manager [...] was very confrontational and said [...] what did you have that you had to take forty five minutes to speak about?' (interview with MI022). The participants voiced how such attitudes amplified existing difficulties with disclosure that that they experienced as increasing mental health stigma. 'Police officers who are good police officers...they deal with things on their own, [...] they don't want to appear to be vulnerable or incompetent [...] they don't open up' (Interview with MI183).

\section{Influences of Investigative Role on Identity}

The influences of the investigative role on identity were reflected in three subthemes: identity; morality and moral injury and searching for meaning and detachment.

\section{Subtheme 1: Identity}

The participants articulated how exposure to multiple graphic images had a substantial impact on personal views of themselves as damaged and contaminated, perceptions they were reluctant to infiltrate to family life. This view of identity incongruence was captured when a participant commented, '[Y] ou're dealing with somebody and you're using authority, erm, but then when you come home, you're not a police officer anymore, you're dad [...] and you have to change' (interview with MI39). Such changes to their sense of self infiltrated social engagements since work-induced hypervigilance permeated into personal relationships. As one participant observed, 'If you are looking at every new male that $[\ldots]$ you meet in a social environment and you're starting to assess them on a professional level, that's exhausting, you're never switching off' (interview with MI866). 'Grooming the groomers' was voiced as a source of further emotional confusion since the objective was, 'trying to almost befriend the [perpetrator] so that they $[\ldots]$ almost trust you' (interview with MI866).

\section{Subtheme 2: Morality and Moral Injury}

The ICAT investigators articulated a lack of consensus as to the morals that informed their work. One described morals as a protective tool that shielded them from the traumatic content they were exposed to. 'Your morals are...the walls of your castle...you build up these walls and you build up your defences, so you can keep away the bad things' (interview with MI866). For another participant however, morals were framed within the legal structures that defined policing. 'I have a good understanding of what is legal and illegal and, therefore, a good understanding of what is morally acceptable and not acceptable' (interview with MI183).

\section{Subtheme 3: Searching for Meaning and Detachment}

The participants were unanimous in the view that their key motivation as ICAT investigators was the opportunity to make a difference to society by protecting others. However, one participant voiced how they managed the realities of grading indecent images by detaching from meaning. 'So it's just little kids, fine, whatever [ ...] I I just forget about it, it's not sexual, [...]' (interview with MI036). Later, though, this individual described having to take leave from work due to the difficulties of one specific image.

Other investigators over identified with some material that they viewed, 'I've got [young relatives] who are the ages [...] of the children I see being abused in these images[...] I look at it and I think, well, that could be my [young relatives]' (interview with MI866). 


\section{Coping Mechanisms to Manage Distress}

The subthemes captured within this superordinate theme were peer and familial support, adaptive and maladaptive coping and breaking point and burnout.

\section{Subtheme 1: Peer and Familial Support}

The ICAT investigators articulated that family support was a crucial and substantial buffer for psychological distress but unrecognised by the organization. One participant described how their partner had filled the therapeutic gap as best they could. 'I've been with...my [partner] for sixteen years and [they are]...a tremendously supportive part of my life, [they are] probably my...my principle support mechanism' (interview with MI022). Since their peers alone understood the traumas associated with the role, the participants also voiced considerable reliance upon collegial support for their psychological wellbeing. 'If there's like a certain part of a video that's extreme, I think if I spoke about that part of the video $[\ldots]$ then $[\ldots]$ it's out there, and it's not just with me' (interview with MI7541).

\section{Subtheme 2: Adaptive and Maladaptive Coping}

The most common form of effective coping to relieve stress and prime feelings of achievement was exercise and physical activity, ' $\ldots[\mathrm{t}$ ] 0 relieve [themselves] from [...] work burdens $[\ldots]$ going out hillwalking and cycling all the time' (interview with MI022). Two participants, however, identified exercising as iconic with alone time, often perpetuating feelings of loneliness through isolation.

All participants spoke of how they used a dark 'gallows' humour to help them bond with fellow investigators in their mutual understanding of the difficult role they undertook. 'I've got a very dark sense of humour, which helps in these situations. The people around me [...] say, if you don't laugh you'll cry' (interview with MI7541). Another tactic to neutralise the intensity of their work was to keep the audio off on distressing video, especially those featuring young children. 'There's something in my head, which allows me to look at a video [...] because I' $m$ not hearing the audio, I can try and view that in a...in a relatively dispassionate way' (interview with MI022). Not all coping mechanisms were adaptive or helpful. One participant described using alcohol to manage their distress, 'I'm just going to sit and get gassed tonight $[. .$.$] I don't really want to talk about it' (interview$ with MI022). However, these feelings inevitably leaked and were then released as emotional flooding.

I can become very emotional about [laughs] fairly ordinary and stupid things and I find myself some- times sitting in floods of tears and, at the same time, laughing at myself for crying at such a ridiculous thing [laughs]. [...] like, the Pride of Britain TV show, [...] I sit and blub like a child (interview with MI022).

Cognitive avoidance appeared to be an unconscious, but commonly articulated strategy to avoid distressing thoughts. However, the consequences presented as intrusive thoughts and images, reflective of the content observed at work. 'I'll see a child and their face looks exactly the same as the face of a child I've been seeing, you know, being raped and you can't help but make those comparisons' (MI391).

\section{Subtheme 3: Breaking Point and Burnout}

Many participants shared negative thoughts, believing they would not be able to cope with what they saw in the future. During rest days, 3 of the participants described how they experienced the psychosomatic consequences of suppressed, chronic stress. 'When I'm on one of my rest days or annual leave, I become ill [...] my body relaxes and I end up getting a cold or [...] I suffer with mouth ulcers' (interview with MI022). As such, most considered their role as time-limited. 'I'll have to change jobs, it will come to a point where I'll have another one of these [critical incidences] and I think I'll be incapacitated again' (interview with MI036).

\section{Influences of Trauma on Personality, Self and Wellbeing}

The influences of trauma on areas of personality and wellbeing were considerable and reflected in the following four subthemes: two worlds: balancing darkness and light, personality traits and post-traumatic depreciation, trauma and effects and parent and family role.

\section{Subtheme 1: Two Worlds: Balancing Darkness and Light}

All of the participants spoke of a division between their work life - as sullied by darkness and the extremes of humanity, compared to their home life; as symbolic of the love of family and friends and safety. One participant captured the dark side when they said,

I live ...well, I work [...] in a warped world. [...] the norm for me now is [...] if I' $m$ going to find indecent images [...] I would expect to find children from maybe seven or eight up to sixteen being abused orally, vaginally, anally (interview with MI866).

This divide was consistent throughout the data and defined by the researchers as two worlds: darkness and light. Many investigators feared contamination by the dark world, and the potential effects of 'the virus' (interview with MI183) on 
their relationships with friends, partners and families, 'You [partner] don't need to know, because once I describe it to you, you will not un-hear that description...that's not [their] world, that's my world' (interview with MI866). One participant described how the symbolic act of changing out of their uniform drew a line between the two worlds. 'I still see the shirt and tie as a uniform and by taking that off, it just draws a line under the end of the day' (interview with MI866).

\section{Subtheme 2: Personality Traits and Post-traumatic Depreciation}

Most participants believed they had become more cynical in their attitudes towards others and the world, fearing how the impact of these beliefs might skew their view of humanity. '[I]f I spend [...] half of my waking day looking at an ugly side of people and [...] society, do I become cynical? Am I inclined to look at people and, without any evidence, judge them by my experiences?' (interview with MI0122). Significant identity and attitudinal changes were also voiced by the participants.

I can feel it making a difference ... on my view of the world and I can feel it making a ball in my stomach [...]. [E]ventually [...] I'm going to either drop everything and walk out or I'm just going to collapse and just be, like [...] no more (interview with MI036).

\section{Subtheme 3: Trauma and Effects}

Three of the participants undertaking the ICAT role recognised that the developmental trauma (including severe physical abuse, neglect, sexual abuse and domestic violence) they had experienced had left them vulnerable to psychological distress. For example, one recalled how, 'My dad just beat me $[\ldots$.$] . I have scars on my fingers ... where my mother$ sliced it open with a knife, because I tried to take a sandwich, [...]' (interview with MI036). Trauma exposure and inadequate processing of traumatic memories resulted in being haunted by the images. '.. [T] here are images which I've seen, both from within this role and also from within my ordinary policing role, that I will remember ...I suspect all of my life' (interview with MI022). The resultant distress was voiced as insomnia, psychosomatic issues (e.g. stomach pain) or panic attacks.

\section{Subtheme 4: Parent and Family Role}

Many participants believed they had brought work home at times, not sufficiently detaching before entering the "normal' world. One participant described their partner as an important barometer in such instances, '...[M]y [partner] is very good at telling me [...] I think you need to have five minutes to yourself' (interview with MI391). Those investigators with children utilised protective parenting to safeguard their offspring from online exploitation. 'My own kids... will never be left alone in a room with anything that connects to the internet, until they're at least sixteen [laughing]' (interview with MI7541). Following the birth of their children, one interviewee reported how the difficulties of processing indecent images had infiltrated their own psyche. 'I just feel myself kind of being a bit more disturbed when the images come up in front of me [...] particularly seeing, little girls' genitalia [now that I have my own kids]' (interview with MI022).

\section{Discussion}

Findings from this study gave rise to four superordinate themes that reflected the participants' key concerns: impact of organizational role and environment, influences of investigative role on identity, coping mechanisms to manage distress and influences of trauma on personality, self and wellbeing.

Based on their experiences, the researchers analysing the data both held cautious opinions about the archetypal profile characterising police officers. However, these initial assumptions have been challenged through a greater understanding of the extreme vulnerability and emotional susceptibility of ICAT investigators. Several participants observed that the inquiry into their experiences had afforded a cathartic opportunity to consider and express events. ICAT investigators are conditioned to avoid thinking about uncomfortable emotions and it is possible that some of the distress they voiced may have come from the interview process itself, a common side effect of interviews exploring sensitive topics (Decker et al. 2011; Newman and Kaloupek 2005). For the researchers, this realization came through the double hermeneutic characterising IPA, specifically the interplay between the perceiver and the perceived (Smith and Osborn 2008, p. 57).

An important observation was that many participants experienced developmental trauma prior to beginning their investigator role. Those who had experienced developmental trauma of a sexual nature appeared particularly vulnerable to a range of psychologically distressing symptoms and reexperiencing symptoms. According to the Child Welfare Information Gateway (2013, Federal research on adverse childhood experiences, para 6), re-enactment behaviours are a means of attempting to master an understanding of the trauma they endured. These finding are supported in other psychological literature which demonstrates consistent links between childhood trauma and a range of psychological disorders including depression, anxiety and complex PTSD (Brady and Back 2012; Ehlert 2013; Suliman et al. 2009; Torjesen 2019). Data from the current study contributes to 
existing literature by affording an understanding as to how future recruitment strategies may benefit ICAT investigators by screening for underlying developmental and adult trauma consequences such as experiential avoidance, emotional dysregulation and dissociation. This is relevant in the context of online child abuse investigation as re-victimization places these ICAT officers at greater risk for PTSD and dissociation when further exposed to trauma (Arata 2002).

A central contribution was that exposure to distressing images of child exploitation and other extreme content played a role in the degradation of mental health. Views of professional services were unflattering and possibly explained by the generic interventions available through the constabularies, as opposed to needs-led support. This finding is significant in advancing disciplinary understanding regarding more targeted responses for online investigators where training, screening and therapeutic intervention may meaningfully address a current vacuum in managing distress.

As the investigator role involves continuous exposure to traumatic content, learning how to manage and deal with these experiences from an evidence-based perspective is imperative. Cognitive behavioural therapy-based interventions may offer a promising model as they regularly include psychoeducation components to aid others, not only with understanding the links between thoughts, feeling, emotions and physiology but also the connection with trauma (Ehlers and Clark 2000). Given the sexual abuse content of the images viewed by the ICAT investigators trauma-focused cognitive therapy (TF-CBT) may be of particular interest in relation to vicarious trauma. TF-CBT was originally designed for children, adolescents and non-offending caregivers facing the crisis of sexual abuse. It has demonstrated considerable effectiveness in managing emotions resulting from inappropriate sexual behaviours as well as general behaviour problems, as therapeutic interventions are based on trauma focused narratives (Cohen and Mannarino 2019).

Future psychoeducation designs could benefit from effective distress management through evidence based techniques such as mindfulness, calm breathing and grounding techniques (Hawton et al. 1989), or focusing on emotional regulation skills within dialectic behaviour therapy. Whilst this latter bears similarity with other cognitive-behavioural approaches, two critical and unique elements would emphasise its relevance for use with ICAT investigators experiencing emotional turmoil, firstly, its focus on mindfulness and acceptance and secondly, its attention to emotional management techniques (Chapman 2006; Linehan 1987).

The participants' clearly and repeatedly made reference to the two worlds that represented their occupational experiences; these were work and home. The former was described as warped because of its associations with depravity and the latter as representative of safety because of its associations with familial love and purity. Because of these connotations, they were named by the researchers as the dark and the light realm. This separation was described by the participants as a dissociative measure to protect those within the 'light realm' from being contaminated by the 'dark realm', chiming with previous literature about dissociation. For example, Liotti (2004) found dissociation to be a natural consequence of trauma; an attempt at coping with overwhelming emotions or stimuli, as well as difficulties with self-identity arising from complex trauma (Luyten et al. 2020). This natural survival response to trauma appeared to have both pros and cons. For instance, detached from work, the participants felt safe, secure and comforted when they were at home or with their partners. Dissociation also permitted a functioning and essential detachment from empathy and identification with survivors. The cons included the overbearing sense of responsibility, loneliness, hypervigilance, difficulties processing emotions, incongruence with their self and emotional dysregulation.

Such divergent findings raise the question as to what represents healthy, as opposed to unhealthy detachment. Whilst previous authors have focussed upon dissociation as a consequence of trauma, an alternate explanation may derive from the participant who removed their uniform as an iconic separation between the two worlds. This individual demonstrated heightened self-consciousness, advanced compartmentalising skills and pre-conceptualised techniques for managing distress, which deviated from the other interviewees. The implications for practice therefore suggest that building selfawareness into organizational support packages may enable healthy detachment, a topic that would benefit from future research.

Evidence suggested that ICAT investigators were not processing through their most difficult exposure to the graphic, violent and traumatic content e.g. chat logs and videos. Experiential avoidance, a technique used by them, maintained disintegration of their challenging experiences into existing moral schemas, resulting in substantial distress, including intrusive memories and other re-experiencing symptoms. A range of experiential avoidant strategies including cognitive, behavioural and affective, compounded this distress by preventing the memory being processed effectively. Data showed that the rules around emotional processing were both personally and culturally defined. This was evidenced by the participants' reluctance to speak of traumatic experiences lest this biased collegial and organizational opinions about their ability to cope. Social cognitive processing theory (Lepore 2001) may offer a possible solution to processing traumatic content more effectively within the workplace. Lepore's (2001) research on cancer survivors highlighted the importance of positive and supportive peer networks to enhance cognitive and emotional processing by enabling individuals to contemplate and discuss trauma 
related thoughts and feelings. Negative environments that are not open to discussion can compound psychological distress by increasing loneliness and vulnerability to depression. Hence, a significant advance to practice would be the enablement of positive social responses within the workplace which permit the consolidation of trauma memories, reducing the need for processing and attempts to find meaning. This would allow staff to explore thoughts, feelings and meanings about the traumatic content that are the most distressing and aid in balancing skewed views of self, others and the world, as reflected in the cognitive triad of trauma (Center for Substance Abuse Treatment 2014). Whilst peer support evidentially affords considerable benefit and camaraderie to those experiencing organizational stress and anxieties (Agarwal et al. 2020; Creamer et al. 2012), given the complex nature of the psychological conditions experienced by the ICAT investigators, it may not offer sufficiently nuanced intermediation as a stand-alone intervention. Thus, the long-term viability of ICAT investigators in this role is questionable.

A thought-provoking finding was of the archetypal masculine values within the environment. This concept appeared a highly complex area made up of contrasting perspectives. Organizational responsibility played a central role, as mental health stigma promoted isolation, low mood and stress that reduced team coherence and communication, a finding endorsed by Papazoglou (2013). The data demonstrated how this fed into and amplified existing schema characterising macho perceptions of 'good police officers' as self-reliant, a culturally defined ontology mediated according to organizational pro forma. Since masculine culture is suggested to play a strong role in completed male suicides (Oliffe and Phillips 2008), the topic of archetypal masculinity introduces ethical challenges for policing organizations, who are mandated to safeguard employee wellbeing. In negative organizational environments, ICAT investigators may feel abandoned by their employers, as evidenced in the current research, taking responsibility for their own welfare. This further emphasises the need for specific intervention with online investigators, to promote a positive attitude towards mental health and seeking support when required.

The participants' narrative communicated how the trauma associated with their role had overwhelmed their ability to cope. This abuse of their emotional agency was intensified as they bore witness to gross violation against children on a scale that outstripped their ability to act. Such governance of their actions disempowered their moral aspirations to protect, leaving them at the mercy of events, whereby initiating moral injury. For all but one participant, this eroded their sense of meaning and place in the world.

Whilst moral injury is not currently classified as a mental health disorder, the revised symptom clusters characterising PTSD (intrusion, avoidance, negative alterations in cognition and mood and alterations in arousal and activity) now offer treatment options more closely attuned to moral injury (Jones 2020). However, rather than medicalising ethical behaviour or pathologising emotions (Jones 2020, p. 128), a response that recognises the irreconcilable and complex dilemmas ICAT investigators face as the result of their moral injury is needed as an adjunct to psychological support.

An important consideration throughout data analysis is how the dual professions of the analysts, as psychologists and researchers, may have influenced interpretation and explanation of the findings. Throughout the research process, the researchers met numerous times, to weigh the influence of their professions over interpretation. This constant monitoring of self, allowed them to reframe their understanding within the shifting context to which it applied. Unexpectedly, it was data gathering, rather than analysis that was effected by their professional identity. These became known to the participants via the participants email signatures, leading one interviewee to frequently refer to CBT, possibly as a way to impress their knowledge. Seemingly, foreknowledge affects data. Arguably, however, this introduces multiple perspectives of reality and endorses the impact of subjectivity in a way consistent with IPA.

\section{Limitations}

The limitations of the current study are that although key areas of concern have been highlighted, the severity and frequency of these issues have yet to be explored. Interviews had to take place remotely via videoconferencing software due to Covid19 restrictions. There is no way of knowing how the Covid-19 lockdown may have influenced responses. Individuals who initially registered to take part in the study may no longer have felt confident to participate. Conversely being interviewed in a safe place may have increased the participants' comfort with discussing sensitive topics. With the interviews entirely audio based, this may have impeded the relationship between interviewer and participant. The small sample size may have threatened the validity and generalisability of the findings however as IPA does not seek data saturation, generalisability is not its primary aim (Smith and Osborn 2008). This research was an exploratory overview of moral injury and psychological distress of investigators of online child sexual exploitation. Consequently, many relevant clinical areas could have been focused on in more depth but were beyond the scope of the current study.

\section{Study Implications}

Given the limited sample size over-generalization of the potential implications cannot be made. However, the collaboration formed between the constabulary in the South West of the UK has led to innovative changes in practice 
based upon the researchers' recommendations regarding the support offered to ICAT investigators (precise details are not yet known as these moderations are ongoing). The outcomes from these changes will be measured by the researchers to assess the impact upon the wellbeing of the ICAT investigators. These data will support theories for change that will both inform the design of planned future research to design a psychoeducation programme for use with ICAT and a table identifying the key symptoms of moral injury and trauma to aid early intervention, also forthcoming. This positive response endorses the strength of knowledge exchange between academia and policing and validates the need for improvements to the psychological support systems and organizational care, found lacking in the results.

\section{Conclusion}

This research explored moral injury and belief change within the context of the lived experience of investigators of child online exploitation. Several key areas of interest were highlighted including a lack of psychological training, non-focused psychological screening and generic support services, poor coping mechanisms and the consequences of long-term exposure to traumatic content. Future research could explore the clinical aspects of reported difficulties in more depth to examine the frequency and severity of psychological difficulties of online investigators. A further targeted exploration of the clinical context and environment may be useful to suggest further interventions and support online investigators in their role. Longitudinal research may provide an effective monitoring tool to explore the long-term effects and resilience of exposure to this form of traumatic content and its effects. Finally, evidence from the data suggested that there is substantial potential for moral injury, negative belief change and other psychological distress from the exposure to trauma content and the organizational difficulties that compound the role.

Author Contribution PL and VK conceived and designed the research. MD and KT gathered and analysed the data. All the authors read and approved the manuscript.

Availability of Data and Materials The authors agree that, subject to the requirements or limitations imposed by research laws and regulations, any materials and data that are reasonably requested by others are available from a publicly accessible collection or will be made available in a timely fashion, at reasonable cost and in limited quantities to members of the scientific community for non-commercial purposes.

\section{Declarations}

Conflict of Interest The authors declare no competing interests.

\section{References}

Agarwal B, Brooks SK, Greenberg N (2020) The role of peer support in managing occupational stress. a qualitative study of the sustaining resilience at work intervention. Workplace Health Saf 68(2):57-64. https://doi.org/10.1177/2165079919873934

Arata CM (2002) Child sexual abuse and sexual revictimization. Clin Psychol Sci Pract 9(2):135-164. https://doi.org/10.1093/clipsy.9.2.135

Barnes HA, Hurley RA, Taber KH (2019) Moral injury and PTSD: often co-occurring yet mechanistically different. J Neuropsychiatry Clin Neurosci 31(2):A4-103. https://doi.org/10.1176/appi. neuropsych. 19020036

Bartol CR, Bartol AM (2004) Introduction to forensic psychology. Sage

Bourke ML, Craun SW (2014) Secondary traumatic stress among internet crimes against children task force personnel: impact, risk factors and coping strategies. Journal of Sexual Abuse 26(6):586609. https://doi.org/10.1177/1079063213509411

Brady KT, Back SE (2012) Childhood trauma, post-traumatic stress disorder and alcohol dependence. Alcohol Res 34(4):408-413. https://www.ncbi.nlm.nih.gov/pmc/articles/PMC3860395/pdf/ arcr-34-4-408.pdf

Burns CM, Morley J, Bradshaw R, Domene J (2008) The emotional impact on and coping strategies employed by police teams investigating internet child exploitation. Traumatology 14(2):20-31. https://doi.org/10.1177/1534765608319082

Burruss GW, Holt TJ, Wall-Parker A (2018) The hazards of investigating internet crimes against children: digital evidence handlers' experiences with vicarious trauma and coping behaviors. Am J Crim Justice 42(3):433-447. https://doi.org/10.1007/ s12103-017-9417-3

Caldero MA, Crank JP (2011) Police ethics: the corruption of noble cause. Elsevier, Inc

Center for Substance Abuse Treatment (2014) Trauma-informed care in behavioral health services

Chapman AL (2006) Dialectical behaviour theory. Psychiatry 3(9):6268. https://www.ncbi.nlm.nih.gov/pmc/articles/PMC2963469/pdf/ PE_3_9_62.pdf

Child Welfare Information Gateway (2013) Long term consequences of child abuse and neglect. Retrieved June 01, 2021, from https:// www.bath.ac.uk/publications/library-guides-to-citing-referencing/ attachments/american-psychological-association-style-guide-7th. pdf

Cohen JA, Mannarino AP (2019) Trauma-focused cognitive behavioral therapy for childhood traumatic separation. Child Abuse Negl 92:179-195. https://doi.org/10.1016/j.chiabu.2019.03.006

College of Policing (2020) Responding to trauma in policing. Retrieved August 8, 2020, from https://oscarkilo.org.uk/app/uploads/2020/ 12/Hesketh_Tehrani_Responding-to-trauma-in-policing-a-pract ical-guide.pdf

Crank J, Flaherty D, Giacomazzi A (2007) The noble cause: an empirical assessment. J Crim Just 35(1):103-116. https://doi.org/10. 1016/j.jcrimjus.2006.11.019

Creamer MC, Varker T, Bisson J, Darte K, Greenberg N, Lau W, Moreton G, O’Donnell M, Richardson D, Ruzek J, Watson P, Forbes D (2012) Guidelines for peer support in high-risk organizations: an international consensus study using the Delphi Method. J Trauma Stress 25(2):134-141. https://doi.org/10.1002/jts.21685

Currier JM, Holland JM, Malott J (2015) Moral injury, meaning making, and mental health in returning veterans. J Clin Psychol 71(3):229-240. https://doi.org/10.1002/jclp.22134

Decker SE, Naugle AE, Carter-Visscher R, Blankenship AS, Bell KM (2011) Ethical issues on research on sensitive topics: participants' experiences of distress and benefit. J Empir Res Hum Res Ethics 6(3):55-64. https://doi.org/10.1525/jer.2011.6.3.55 
Ehlers A, Clark DM (2000) A cognitive model of posttraumatic stress disorder. Behav Res Ther 38(4):319-345. https://doi.org/10.1016/ S0005-7967(99)00123-0

Ehlert U (2013) Enduring psychobiological effects of childhood adversity. Psychoneuroendocrinology 38(9):1850-1857. https://doi.org/ 10.1016/j.psyneuen.2013.06.007

Evans BJ, Coman GJ, Stanley RO, Burrows GD (1993) Police officers' coping strategies: an Australian police survey. Stress Med 9(4):237-246. https://doi.org/10.1002/smi.2460090406

Garrigan B, Adlam ALR, Langdon PE (2018) Moral decision-making and moral development: towards an integrative framework. Dev Rev 49:80-100. https://doi.org/10.1016/j.dr.2018.06.001

Grierson J (2020) Watchdog reveals $8.8 \mathrm{~m}$ attempts to access online child abuse in April. Retrieved September 29, 2020, from https:// www.theguardian.com/society/2020/may/20/watchdog-reveals$88 \mathrm{~m}$-attempts-to-access-online-child-abuse-in-april (Accessed 29 Sep 2020)

Griffin BJ, Purcell N, Burkman K, Litz BT, Bryan CJ, Schmitz M, Villierme C, Walsh J, Maguen S (2019) Moral injury: an integrative review. J Trauma Stress 32(3):350-362. https://doi.org/10.1002/ jts. 22362

Harr RN (2005) Factors affecting the decision of police recruits to "drop out" of police work. Police Q 8(4):431-453. https://doi.org/10.1177/ 1098611103261821

Hawton K, Salkovskis PM, Kirk J, Clark DM (1989) Cognitive behaviour therapy in psychiatry: a practical guide. Oxford Medical Publications

Holt TJ, Blevins KR, Burruss GW (2012) Examining the stress, satisfaction, and experiences of computer crime examiners. J Crime Justice 35(1):35-52. https://doi.org/10.1080/0735648X.2011. 631401

Jones E (2020) Moral injury in a context of trauma. Br J Psychiatry 216(3): Themed Issue: Disasters and Trauma, 127-128.https://doi. org/10.1192/bjp.2020.46

Keane TM, Fairbank JA, Caddell JM, Zimergin RT, Bender ME (1985) A behavioral approach to assessing and treating post-traumatic stress disorder in Vietnam veterans. In C. R. Figley (Ed.), Trauma and its wake. The study and treatment of post-traumatic stress disorder, Vol. 1. (pp. 257-294). Brunner/Mazel

LaMotte AD, Murphy CM (2017) Trauma, posttraumatic stress disorder symptoms, and dissociative experiences during men's intimate partner violence perpetration. Psychol Trauma 9(5):567-574. https://doi.org/10.1037/tra0000205

Lee, P. (2018). Reaper Force - Inside Britain's drone wars. Chicago: John Blake Limited.

Lepore SJ (2001) A social-cognitive processing model of emotional adjustment to cancer. In A. Baum \& B. L. Andersen (Eds.), Psychosocial interventions for cancer (p. 99-116). American Psychological Association. https://doi.org/10.1037/10402-006

Linehan MM (1987) Dialectical behaviour therapy for borderline personality disorder: theory and method. Bull Menninger Clin 51(3):261. https://doi.org/10.1037/00333204.41.4.472

Liotti G (2004) Trauma, dissociation, and disorganized attachment: three strands of a single braid. Psychother Theor Res Pract Train 41(4):472. https://doi.org/10.1037/0033-3204.41.4.472

Litz BT, Kerig PK (2019) Introduction to the special issue on moral injury: conceptual challenges, methodological issues, and clinical applications. J Trauma Stress 32(3):341-349. https://doi.org/10. $1002 /$ jts. 22405

Litz BT, Stein N, Delaney E, Lebowitz L, Nash WP, Silva C, Maguen S (2009) Moral injury and moral repair in war veterans: a preliminary model and intervention strategy. Clin Psychol Rev 29(8):695-706. https://doi.org/10.1016/j.cpr.2009.07.003

Lopez KA, Willis DG (2004) Descriptive versus interpretive phenomenology: their contributions to nursing knowledge. Qual Health Res 14(5):726-735. https://doi.org/10.1177/1049732304263638
Luyten P, Campbell C, Fonagy P (2020) Borderline personality disorder, complex trauma, and problems with self and identity: a social-communicative approach. J Pers 88(1):88-105. https://doi. org/10.1111/jopy. 12483

McCormak L, Riley L (2016) Medical discharge from the "family", moral injury and a diagnosis of PTSD: Is psychological growth possible in the aftermath of policing trauma? Traumatology 22(1):19-28. https://doi.org/10.1037/TRM0000059

McCreary DR, Fong I, Groll DL (2017) Measuring policing stress meaningfully: establishing norms and cut-off values for the operational and organizational police stress questionnaires. Police Pract Res Int J 18(6):612-623. https://doi.org/10.1080/15614263.2017. 1363965

McQuerrey Tuttle, B., Stancel, K., Russo, C., Koskelainen, M., \& Papazoglou, K. (2019). Police moral injury, compassion fatigue, and compassion satisfaction: A brief report. Salus Journal, 7(1), 42-45.

Molendijk T (2018) Toward an interdisciplinary conceptualization of moral injury: from unequivocal guilt and anger to moral conflict and disorientation. New Ideas Psychol 51:1-8. https://doi.org/10. 1016/j.newideapsych.2018.04.006

Nash WP (2019) Commentary on the special issue on moral injury: unpacking two models for understanding moral injury. J Trauma Stress 32(3):465-470. https://doi.org/10.1002/jts.22409

Neubauer BE, Witkop CT, Vario L (2019) How phenomenology can help us learn from the experiences of others. Perspect Med Educ 8(2):90-97. https://doi.org/10.1007/s40037-019-0509-2

Newman E, Kaloupek DG (2005) The risks and benefits of participating in trauma focused research studies. J Trauma Stress 17(5):383-394. https://doi.org/10.1023/B:JOTS.0000048951. $02568.3 \mathrm{a}$

Oliffe JL, Phillips MJ (2008) Men, depression and masculinities: a review and recommendations. J Men's Health 5(3):194-202. https://doi.org/10.1016/j.jomh.2008.03.016

Papazoglou K (2013) Conceptualizing police complex spiral trauma and its applications in the police field. Traumatology 19(3):196209. https://doi.org/10.1177/1534765612466151

Pogrebin MR, Poole ED (1991) Police and tragic events: the management of emotions. J Crim Just 19(4):395-403. https://doi.org/10. 1016/0047-2352(91)90036-U

Powell MB, Cassematis P, Benson MS, Smallbone S, Wortley R (2014) Police officers' perceptions of the challenges involved in Internet Child Exploitation investigation. Policing 37(3):543-557. https:// doi.org/10.1108/PIJPSM-08-2013-0080

Rivard JM, Dietz P, Martell D, Widawski M (2002) Acute dissociative responses in law enforcement officers involved in critical shooting incidents: the clinical and forensic implications. J Forensic Sci 47(5):1-8. Retrieved September 13, 2020, from https://www. hptinstitute.com/wp-content/uploads/2014/01/Acute-Dissociati ve-Responses.pdf

Rudofossi D (2007) Working with traumatized police officer-patients. A clinician's guide to complex PTSD syndromes in public safety professionals, Baywood

Shay J (2010) Achilles in Vietnam: Combat trauma and the undoing of character. Simon \& Schuster

Shay J (2014) Moral injury. Psychoanal Psychol 31(2):182-191. https:// doi.org/10.1037/a0036090

Shay J, Munroe J (1998) Group and milieu therapy for veterans with complex posttraumatic stress disorder. In P. A. Saigh, J. D. Bremner (Eds.). Posttraumatic stress disorder: A comprehensive text (pp. 391-413) Allyn \& Bacon

Smith JA, Flowers P, Larkin M (2009) Interpretative phenomenological analysis: theory, method and research. Sage

Smith JA (1999) Towards a relational self: social engagement during pregnancy and psychological preparation for motherhood. Br J Soc Psychol 38(4):409-426. https://doi.org/10.1348/ 014466699164248 
Smith JA, Osborn M (2008) Interpretative phenomenological analysis. In Smith, J.A. (Eds.). Qualitative psychology: a practical guide to research methods (3rd Ed., pp. 53-80.). Sage

Smith JA, Osborn M (2015) Interpretative phenomenological analysis as a useful methodology for research on the lived experience of pain. Br J Pain 9(1):41-42. https://doi.org/10.1177/2049463714 541642

Suliman S, Mkabile SG, Fincham DS, Ahmed R, Stein DJ, Seedat S (2009) Cumulative effect of multiple trauma on symptoms of posttraumatic stress disorder, anxiety, and depression in adolescents. Compr Psychiatry 50(2):121-127. https://doi.org/10.1016/j.comppsych.2008.06.006
Torjesen I (2019) Childhood trauma doubles risk of mental health conditions. BMJ 364:1854. https://doi.org/10.1136/bmj.1854

Zięba M, Wiecheć K, Biegańska-Banaś J, Mieleszczenko-Kowszewicz W (2019) Coexistence of post-traumatic growth and post-traumatic depreciation in the aftermath of trauma: qualitative and quantitative narrative analysis. Front Psychol 10:687. https://doi.org/10. 3389/fpsyg.2019.00687

Publisher's Note Springer Nature remains neutral with regard to jurisdictional claims in published maps and institutional affiliations. 